Check for updates

Cite this: J. Mater. Chem. B, 2021 9, 4120

Received 21st January 2021, Accepted 3rd May 2021

DOI: 10.1039/d1tb00129a

rsc.li/materials-b

\section{Mixed polymer and bioconjugate core/shell electrospun fibres for biphasic protein release $\uparrow$}

\author{
Inchirah Adala, ${ }^{a}$ Jopeth Ramis, ${ }^{a}$ Cynthia Ntone Moussinga, ${ }^{a}$ Isabella Janowski, ${ }^{a}$ \\ Mahetab H. Amer, (D) ${ }^{\mathrm{b}}$ Andrew J. Bennett, ${ }^{\mathrm{c}}$ Cameron Alexander (D) ${ }^{\mathrm{a}}$ and \\ Felicity R. A. J. Rose (D) *a
}

\begin{abstract}
Effective regenerative medicine requires delivery systems which can release multiple components at appropriate levels and at different phases of tissue growth and repair. However, there are few biomaterials and encapsulation techniques that are fully suitable for the loading and controlled release of multiple proteins. In this study we describe how proteins were physically and chemically loaded into a single coaxial electrospun fibre scaffold to obtain bi-phasic release profiles. Cyto-compatible polymers were used to construct the scaffold, using polyethylene oxide (PEO) for the core and polycaprolactone $(\mathrm{PCL})$ reacted or mixed with (bis-aminopropyl)polyether (Jeffamine ED2003; JFA) for the shell. Horseradish peroxidase (HRP), a model protein, was loaded in the core and functionalised onto the scaffold surface by coupling of protein carboxyl groups to the available polymer amine groups. Fibre morphologies were evaluated by scanning electron microscopy (SEM) and transmission electron microscopy (TEM) and functional group content was determined using $X$-ray photoelectron spectroscopy (XPS) and time-of-flight secondary ion mass spectrometry (TOF SIMS). Hydrophobicity profiles of the fibres before and after protein loading were evaluated by water contact angle (WCA) and the mechanical properties of the electrospun scaffolds were determined by performing tensile tests. The electrospun fibre scaffolds generated by reacting PEO/PCL with 1,6-diaminohexane and those from mixing PEO/PCL with JFA were further characterised for protein conjugation and release. Fibres prepared by the mixed PEO/PCL/JFA system were found to be the most appropriate for the simultaneous release of protein from the core and the immobilisation of another protein on the shell of the same scaffold. Moreover, JFA enhanced scaffold properties in terms of porosity and elasticity. Finally, we successfully demonstrated the cytocompatibility and cell response to protein-loaded and -conjugated scaffolds using HepG2 cells. Enhanced cell attachment ( 2.5 fold) was demonstrated using bovine serum albumin (BSA)-conjugated scaffolds, and increased metabolic activity observed with retinoic acid (RA)-loaded scaffolds (2.7 fold).
\end{abstract}

\section{Introduction}

Biotherapeutics, such as proteins and peptides, are of increasing interest for the treatment of many diseases and also in the field of regenerative medicine. ${ }^{1}$ For tissue engineering purposes, such biologicals allow the mimicking of the natural tissue environment where many of these molecules, such as growth factors and cytokines, are secreted by cells and sequestered within the extracellular matrix (ECM). ${ }^{1}$ These molecules are necessary for

\footnotetext{
${ }^{a}$ School of Pharmacy, University of Nottingham, Nottingham, UK. E-mail: felicity.rose@nottingham.ac.uk

${ }^{b}$ School of Molecular and Cellular Biology, University of Leeds, Leeds, UK

${ }^{c}$ School of Life Sciences, University of Nottingham, UK

$\dagger$ Electronic supplementary information (ESI) available. See DOI: 10.1039/ d1tb00129a
}

cell-cell communication, modulation of cell attachment and to drive cell differentiation or maturation. ${ }^{2,3}$ They all function in a synchronised manner in order to achieve normal tissue function and guide successful tissue repair or regeneration. Hence, the use of single protein delivery systems in tissue engineering is inherently limiting and does not represent the physiological environment. ${ }^{2,4}$ There is accordingly an urgent need to develop delivery systems which are effective for multiple proteins, ${ }^{5}$ ideally in which the individual proteins can be released at distinct rates. ${ }^{6}$

Protein delivery is a challenge due to the limited stability during formulation, storage, in vitro and in vivo release. ${ }^{7}$ Proteins can breakdown due to environmental factors such as low or high $\mathrm{pH}$, ionic strength, or inactivation by enzymes. ${ }^{7}$ To this end, a number of materials have been used to protect therapeutic proteins by physical separation from any unfavourable environments in an organism prior to delivery. ${ }^{7}$ The chosen 
biomaterial has to be compatible with the protein, and also amenable to an encapsulation technique. ${ }^{7}$ In the case of multiple protein delivery, finding a suitable biomaterial and an encapsulation technique compatible with multiple proteins remains challenging.

Amongst the many technologies for preparing scaffold materials for 3D cell culture and tissue growth, coaxial electrospinning has emerged as a promising approach. This method can produce well-defined and multi-component fibres, with fibre diameters ranging from tens of nanometres to multimicrons. ${ }^{8,9}$ These fibres offer properties important for cell culture including a large surface area, high molecular permeability through the scaffold, and tuneable porosity. ${ }^{10}$ Furthermore, coaxial electrospinning enables the formulation of differentially functionalised core-shell fibres and this in turn can lead to significant practical advantages. ${ }^{11,12}$ These are that diverse guest molecules can be partitioned within and on the layered core-shell structures, enabling, in principle, the simultaneous or phased release of multiple cell-signalling or other bioactive agents. These can range from hydrophobic small molecule inhibitors through to hydrophilic biomacromolecules such as proteins and nucleic acids. ${ }^{13}$ In addition, through variation of the individual materials used for the core and shell regions of the fibres, coaxial electrospinning allows for fine control in the release of encapsulated agents to a much greater extent than for fibres produced by single-nozzle electrospinning. ${ }^{14}$

In this study, proteins were physically and chemically loaded into and onto coaxial electrospun fibres in order to obtain biphasic release profiles. Proteins were covalently attached on the surface of the fibre (i.e. the shell), where cells can access the protein via direct contact. This mimics the interaction between cells and ECM-bound growth factors found in vivo. ${ }^{15}$ While in the core of the fibre, the proteins were physically blended within the polymer to allow subsequent continuous release to the surrounding environment.

Cytocompatible polymers were used to construct the scaffold, in this case polyethylene oxide (PEO) for the core and a polycaprolactone (PCL)/O,O'-bis(2-aminopropyl)polypropylene glycol-block-polyethylene glycol-block-polypropylene glycol
(Jeffamine, JFA) mixture for the shell. PEO was chosen in order to load bioactive molecules in the fibre core without exposing them to organic solvents. PCL was selected owing to its mechanical properties and high solubility in organic solvents typically used in electrospinning processes. ${ }^{16,17}$ However, PCL does not contain functional groups that facilitate high yield protein conjugation. Therefore, two main approaches for covalent attachment of proteins at the scaffold surface were evaluated, (a) the aminolysis of PEO/PCL scaffold post electrospinning by reaction with 1,6-diaminohexane and (b) the use of a PCL/JFA blend. JFA was chosen as it contains two amine-terminal groups attached to each end of a polyether backbone. ${ }^{18}$ In addition to the reactive $\mathrm{NH}_{2}$ termini, the hydrophilic polyether backbone was deemed suitable in order to improve the scaffold's flexibility and wettability. Despite the interesting properties of JFA polymers, only a few studies have reported their use in electrospinning ${ }^{19,20}$ and none in coaxialelectrospinning. In our work, we showed that the use of JFA in a coaxial electrospun scaffold, facilitates the production of a multiple protein delivery system, in comparison to aminolysis and other multi-step treatments such as layer by layer functionalization, polymer coating or grafting ${ }^{21}$ Additionally, we demonstrated that JFA enhanced scaffold properties in terms of porosity and elasticity.

\section{Materials and methods}

\subsection{Preparation of PEO/PCL and PEO/PCL/JFA core-shell electrospun membranes}

Pre-weighed polyethylene oxide (PEO) (200 kDa, $400 \mathrm{kDa}$, and $900 \mathrm{kDa})$, polycaprolactone (PCL) $\left(80000 \mathrm{~g} \mathrm{~mol}^{-1}\right), O, O^{\prime}$-bis(2aminopropyl)polypropylene glycol-block-polyethylene glycolblock-polypropylene glycol (Jeffamine, $1900 \mathrm{~g} \mathrm{~mol}^{-1}$; JFA) (all purchased from Sigma Aldrich, UK) were dissolved in different solvent systems, respectively, as shown in Table 1.

Bioactive molecules horseradish peroxidase (HRP) (Sigma Aldrich, UK, P8375) and retinoic acid (RA) (Sigma Aldrich, UK), were mixed and homogenised with deionised water prior to adding PEO $200 \mathrm{kDa}$.

Table 1 Electrospinning parameters

\begin{tabular}{|c|c|c|c|c|c|}
\hline Polymer & Concentration (\%) & Solvent (v/v) & Flow rate & Distance $(\mathrm{cm})$ & Voltage $(\mathrm{kV})$ \\
\hline \multicolumn{6}{|c|}{ PEO(900 kDa)/PCL } \\
\hline $\operatorname{PEO}(900 \mathrm{kDa})$ & 4 & DIW & $200\left(\mu \mathrm{L} \mathrm{h}{ }^{-1}\right)$ & \multirow[t]{2}{*}{23} & \multirow[t]{2}{*}{16} \\
\hline PCL & 10 & Chloroform/DMF $(8: 2)$ & $1.5\left(\mathrm{~mL} \mathrm{~h}^{-1}\right)$ & & \\
\hline \multicolumn{6}{|c|}{$\mathrm{PEO}(400 \mathrm{kDa}) / \mathrm{PCL}$} \\
\hline $\operatorname{PEO}(400 \mathrm{kDa})$ & 6 & DIW & $200\left(\mu \mathrm{L} \mathrm{h}{ }^{-1}\right)$ & \multirow[t]{2}{*}{23} & \multirow[t]{2}{*}{23} \\
\hline PCL & 10 & Chloroform/DMF $(8: 2)$ & $1.5\left(\mathrm{~mL} \mathrm{~h}^{-1}\right)$ & & \\
\hline \multicolumn{6}{|c|}{ PEO(200 kDa)/PCL } \\
\hline $\operatorname{PEO}(200 \mathrm{kDa})$ & 16 & DIW & $200\left(\mu \mathrm{L} \mathrm{h}^{-1}\right)$ & \multirow[t]{2}{*}{23} & \multirow[t]{2}{*}{16} \\
\hline PCL & 10 & Chloroform/DMF $(8: 2)$ & $1.5\left(\mathrm{~mL} \mathrm{~h}^{-1}\right)$ & & \\
\hline \multicolumn{6}{|c|}{$\mathrm{PEO}(200 \mathrm{kDa}) / \mathrm{PCL} / \mathrm{JFA}$} \\
\hline $\operatorname{PEO}(200 \mathrm{kDa})$ & 16 & DIW & $200\left(\mu \mathrm{L} \mathrm{h}^{-1}\right)$ & \multirow[t]{2}{*}{13} & \multirow[t]{2}{*}{13} \\
\hline PCL/JFA & 10 & Chloroform/DMF $(8: 2)$ & $1.4\left(\mathrm{~mL} \mathrm{~h}^{-1}\right)$ & & \\
\hline
\end{tabular}


For the core, solutions of PEO were prepared at different concentrations using de-ionised water as solvent: $16 \% \mathrm{w} / \mathrm{v}$ PEO $200 \mathrm{kDa}, 6 \% \mathrm{w} / \mathrm{v}$ PEO $400 \mathrm{kDa}$ and 4\% w/v PEO $900 \mathrm{kDa}$. A stock solution of RA at $100 \mathrm{mM}$ in DMSO was prepared. HRP was dissolved and RA further diluted, prior to electrospinning, in PEO to a final concentration of $15.7 \mu \mathrm{g} \mathrm{mL}^{-1}$ and $10 \mu \mathrm{M}$ respectively. For the shell, chloroform and $\mathrm{N}, \mathrm{N}$-dimethylformamide (DMF) were used at a ratio of $(8: 2)$ for dissolving $10 \% \mathrm{w} / \mathrm{w}$ PCL with increasing JFA concentrations of $5 \%, 6 \%$, $7.5 \%, 30 \%, 45 \%$ and $60 \%$ relative to PCL.

Solutions were stirred overnight at room temperature and their conductivity measured using a conductivity meter (Mettler Toledo). Solutions were then loaded into separate disposable plastic syringes for electrospinning and a dual syringe pump was used to deliver the core and shell fluids independently using an electrospinning machine (EC-CLI, IME Technologies, Geldrop, Netherlands). The electrospun fibres were collected on aluminium foil placed onto a grounded rotating mandrel. The applied voltage and the distance between the tip of the spinneret and the collector varied depending on the polymer system. Electrospinning parameters are shown in Table 1.

\subsection{Release study of the core molecule $\mathrm{HRP}_{\mathrm{CM}}$}

The HRP for the release study is denoted as $\mathrm{HRP}_{\mathrm{CM}}$. The release behaviours from pre-weighed loaded fibres were carried out in a shaking incubator at $37{ }^{\circ} \mathrm{C}$ for 22 days in phosphate buffer solution (PBS; pH 7.4) (Sigma Aldrich, UK). At predefined time intervals, $1 \mathrm{~mL}$ of the release medium was withdrawn and replaced with an equal volume of fresh PBS pH 7.4 each time. Protein concentration was determined using the bicinchoninic acid (BCA) assay using the Micro BCA protein assay kit (Thermoscientific, UK) and following the manufacturer's instructions for protein detection in microplate wells.

Activity post-release was measured using the 2,2'-azinobis(3-ethylbenzothiazoline-6-sulfonic acid) diammonium salt (ABTS) assay (Sigma Aldrich, UK). Sample $(100 \mu \mathrm{L})$ was mixed with $100 \mu \mathrm{L}$ of ABTS, $10 \mu \mathrm{L}$ of SDS 0.5\% (w/v; Sigma Aldrich, UK) was added to stop the reaction after $15 \mathrm{~min}$, then the absorbance measured at $405 \mathrm{~nm}$ using a Tecan Infinite M200 plate reader (Tecan Reading, UK).

Data were obtained from three independent experiments $(n=3)$.

\subsection{Surface functionalisation and $\mathrm{HRP}_{\mathrm{SM}}$ conjugation}

PEO/PCL scaffolds were aminolyzed by incubation in $10 \%(\mathrm{w} / \mathrm{w})$ 1-6 diaminohexane in isopropanol for different time intervals

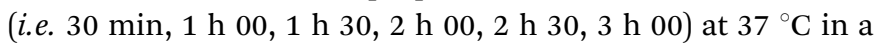
shaking incubator. The scaffolds were washed and kept in isopropanol for $10 \mathrm{~min}$, then washed a further five times in isopropanol, and deionised water. Subsequently, the scaffolds were dried in a chemical fumehood at RT for $24 \mathrm{~h}^{22,23}$

HRP was also used as a model protein for surface conjugation and is denoted $\mathrm{HRP}_{\mathrm{SM}}$. $\mathrm{HRP}_{\mathrm{SM}}$ was conjugated onto the scaffold surface by reacting the carboxyl groups of the protein with the amine groups introduced to the scaffold via JFA incorporation or aminolysis of the surface layers of the PCL scaffolds. Aminolyzed
$\mathrm{PEO} / \mathrm{PCL}$ and PEO/PCL/JFA scaffolds were cut into disks $(10 \mathrm{~mm}$ in diameter) and placed in HRP solution $\left(50 \mu \mathrm{g} \mathrm{mL}{ }^{-1}\right)$ for $30 \mathrm{~min}$ at $37{ }^{\circ} \mathrm{C}$ in a shaking incubator. The scaffolds were then covered with $250 \mu \mathrm{L}$ of $50 \mathrm{mM}$ MES solution buffer $(\mathrm{pH}=6), 125 \mu \mathrm{L}$ of $68 \mathrm{mM}$ EDC and $125 \mu \mathrm{L} 68 \mathrm{mM}$ S-NHS as a single solution (all from Sigma Aldrich, UK). This technique is referred to as EDC-NHS treatment. The samples were then placed on a shaker at RT for different time intervals (i.e. 1 h, 2 h, 3 h, 4 h). Finally, the scaffolds were washed in PBS, and the activity of the conjugated HRP was determined over time by covering the samples with $3,3^{\prime}, 5,5^{\prime}$-tetramethylbenzidine substrate solution (TMB) (Sigma Aldrich, UK) for $15 \mathrm{~min}$. Images of the scaffolds were taken using a digital camera and colour intensity was quantified using Image $1.52 \mathrm{~h}$ software from the ImageJ package Fiji. $^{24}$ Data were obtained from three independent experiments $(n=3)$.

\subsection{Bovine serum albumin (BSA) conjugation}

$\mathrm{PEO} / \mathrm{PCL} / \mathrm{JFA}$ scaffolds were cut into discs of $10 \mathrm{~mm}$ in diameter, placed in BSA (Sigma Aldrich, UK) solution $\left(0.4 \mathrm{mg} \mathrm{mL}^{-1}\right)$ for $30 \mathrm{~min}$ at $37^{\circ} \mathrm{C}$ in a shaking incubator. The scaffolds were then covered with $250 \mu \mathrm{L}$ of $50 \mathrm{mM}$ MES solution buffer $(\mathrm{pH}=6)$, $125 \mu \mathrm{L}$ of $68 \mathrm{mM}$ EDC and $68 \mathrm{mM}$ S-NHS as a single solution (all from Sigma Aldrich, UK). The samples were then placed on a shaker at RT for an hour and washed in PBS. Data were obtained from three independent experiments $(n=3)$.

\subsection{Scaffold characterisation}

Scaffold and fibre morphology. Following gold coating for 90s using a POLARON SC7640 sputter coater, scanning electron microscopy (SEM; Carl Zeiss Ultra) imaging was carried out to determine fibre morphology (average fibre diameter, and the porosity before and after functionalisation) for all scaffolds. The average fibre diameter was calculated from 100 measurements based on 25 measurements from five different SEM images in total and were analysed using Image software. $^{24}$

In order to study internal pore size, the scaffolds were cryofrozen in liquid nitrogen and ruptured before sputter coated with gold. Average pore diameter was calculated upon five different SEM images, from which 100 measurements in total were analysed using Image $1.52 \mathrm{~h}$ software from the ImageJ package Fiji. ${ }^{24}$

Transmission electron microscopy (TEM, FEI Tecnai G2 12 Biotwin) was carried out to determine the core/shell structure of the coaxial fibres. Images were recorded at $100 \mathrm{kV}$.

$\mathrm{X}$-Ray photoelectron microscopy. Changes in surface composition of the PEO/PCL scaffold before and after aminolysis were analysed using X-ray photoelectron microscopy (Kratos AXIS ULTRA) with a mono-chromated Al $k \alpha$ X-ray source (1486.6 eV) operating at $10 \mathrm{~mA}$ emission current and $12 \mathrm{kV}$ anode potential $(120 \mathrm{~W}) \mathrm{A}$ charge neutraliser filament was used to prevent surface charging. Hybrid slot mode was used when measuring a sample area of approximately $0.5 \mathrm{~mm}^{2}$. The analysis chamber pressure was higher than $5 \times 10^{-9}$ mbar. Three areas per sample were analysed. A wide scan at low resolution (1400-5 eV binding energy range, pass energy $80 \mathrm{eV}$, 
step $0.5 \mathrm{eV}$, sweep time 20 minutes) were used to estimate the total atomic\% of the detected elements. High-resolution spectra at pass energy $20 \mathrm{eV}$ with a step of $0.1 \mathrm{eV}$, sweep times of 5, 10 or 20 minutes each were also acquired for photoelectron peaks from the detected elements and these were used to model the chemical composition. The high-resolution spectra were charge corrected to the $\mathrm{C} 1 \mathrm{~s}$ peak set to $285 \mathrm{eV}$. Casaxps (version 2.3.18dev1.0x) software was used for quantification and spectral modelling.

Time-of-flight secondary ion mass spectrometry. Time-offlight secondary ion mass spectrometry (TOF SIMS) was used to confirm the presence of amino groups (of JFA or following aminolysis) and characterise their distribution on the scaffold surface. PEO/PCL, aminolyzed PEO/PCL, PEO/PCL/JFA and $\mathrm{PEO} / \mathrm{PCL} / \mathrm{JFA}$ post water incubation $\left(37{ }^{\circ} \mathrm{C}\right.$ for 7 days $)$ were analysed. Spectra were calibrated to the $\mathrm{CH}, \mathrm{C}-2 \mathrm{H}, \mathrm{C}-3 \mathrm{H}, \mathrm{C} 4 \mathrm{H}$ and $\mathrm{C} 5 \mathrm{H}$ peaks. Positive ion spectra were acquired, and $\mathrm{NH}_{4}{ }^{+}$, $\mathrm{C}_{2} \mathrm{H}_{6} \mathrm{~N}^{+}$peak intensities were measured.

Water contact angle. Surface hydrophilicity of electrospun scaffolds was determined by the water contact angle (WCA) measured by a sessile drop technique, with deionised water and a CAM 200 sessile drop video capture apparatus. WCA was calculated for each image using a Young-Laplace curve fit using the CAM 200 image analysis software; the right and left contact angles were averaged. WCA was determined every second after the water droplet came into contact with the sample.

Mechanical properties of the scaffolds. The tensile properties of the electrospun scaffolds were determined by using a texture analyser (TA HD plus, stable microsystem) with a load cell capacity of $5 \mathrm{~N}$ and a cross-head speed of $10 \mathrm{~mm} \mathrm{~min}^{-1}$ at room temperature. All samples were cut into a dog bone shape and mounted into tensile grips and pulled vertically. Analysis of the scaffold's mechanical properties were calculated from the linear region of the stress-strain diagram (5-25\% strain).

\subsection{Scaffold cytocompatibility and biological response}

The cellular responses to the scaffolds, with and without loaded bioactives, were evaluated by investigating cell attachment and albumin secretion. For both experiments, human HepG2 cells (ATCC, UK) were used from passage 6 to 10. Cells were cultured in Minimum Essential Medium (MEM) supplemented with foetal bovine serum $(10 \% \mathrm{v} / \mathrm{v})$, non-essential amino acid $(1 \% \mathrm{v} / \mathrm{v})$, L-glutamine $(1 \% \mathrm{v} / \mathrm{v}), 100$ units per $\mathrm{mL}$ penicillin, $100 \mu \mathrm{g} \mathrm{mL} \mathrm{m}^{-1}$ streptomycin and $100 \mu \mathrm{g} \mathrm{mL}^{-1}$ of gentamicin/ amphotericin (AB/AM) (all from Sigma Aldrich, UK; HepG2 complete culture media). Cells were maintained at $37{ }^{\circ} \mathrm{C}, 5 \%$ $\mathrm{CO}_{2}$ in air at $95 \%$ relative humidity. Cells were expanded in tissue culture flasks, and media was changed every three days. When $80-90 \%$ confluency was reached, cells were trypsinised with trypsin $(0.25 \% \quad \mathrm{v} / \mathrm{v}) /$ ethylenediamine-tetraacetic acid $(0.02 \% \mathrm{v} / \mathrm{v}$ EDTA) solution. Cells were then centrifuged at $500 \times g$ using a Sigma Laboratory centrifuge 2-16 K (Scientific Laboratory Supplies, UK) and the pellet was resuspended in complete HepG2 culture media.

Prior to cell seeding, $1.13 \mathrm{~cm}^{2}$ diameter scaffolds were cut, placed in inserts, sterilised using a UV lamp $(254 \mathrm{~nm})$ for
$30 \mathrm{~min}$ and placed in a non-tissue culture treated 12 well plate (Corning, UK). Cells were seeded at 100000 cells on various scaffolds and incubated at $37{ }^{\circ} \mathrm{C}, 5 \% \mathrm{CO}_{2}$ in air in HepG2 complete culture media for a period of 3 hours and six days respectively prior to assessment for cell attachment and ELISA.

Cell attachment on the BSA-conjugated scaffold. The conjugation of BSA onto PEO/PCL/JFA scaffolds was performed as described above. BSA-conjugated scaffolds were sterilised and HepG2 cells were seeded as described previously. Cells were incubated at $37{ }^{\circ} \mathrm{C}, 5 \% \mathrm{CO}_{2}$ in air in HepG2 complete culture media for 3 hours to allow cell attachment. Cells were then washed three times with PBS and incubated with Presto blue solution $(10 \% \mathrm{v} / \mathrm{v}$ in HepG2 complete culture media). After $30 \mathrm{~min}, 200 \mu \mathrm{L}$ aliquots (in duplicate) were transferred into a 96 well plate for fluorescence measurement (excitation/emission wavelengths of 560/590 nm). Cell viability was also assessed using the LIVE/DEAD Viability/Cytotoxicity Kit for mammalian cells (Thermo Fisher Scientific, UK) by incubating the scaffolds in culture media supplemented with Calcein AM and ethidium homodimer-1 solution. Live cells were stained in green (calcein-AM), and nuclei of dead cells were stained red (ethidium homodimer-1). Samples were imaged using a Nikon SMZ1500 microscope, equipped with a mercury lamp and an attached Leica DC200 digital camera (Leica Microsystems Ltd, UK).

Albumin ELISA to assess secretion of albumin from HepG2 cells cultured on RA-loaded scaffolds. HepG2 cells were cultured on retinoic acid (RA)-loaded and blank PEO/PCL/JFA scaffolds. Albumin secretion was compared across both conditions to evaluate the biological response to RA release from the scaffold's core during cell culture. The culture supernatant was collected after six days and albumin secretion rates were determined via the competitive albumin human ELISA kit (Abcam, UK, ab108788). Data were obtained from three independent experiments $(n \geq 7)$ and fitted to standards using a four parameter logistic regression curve.

Assessment of cell morphology on scaffolds. SEM images (Carl Zeiss Ultra) were taken on the 6th day of culture to observe cell morphology and proliferation on the scaffolds. Each scaffold was washed with PBS three times. After fixation with $4 \% \mathrm{v} / \mathrm{v}$ paraformaldehyde for $30 \mathrm{~min}$ at $37{ }^{\circ} \mathrm{C}$, the samples were sequentially dehydrated with $20 \%, 30 \%, 40 \%, 50 \%, 60 \%, 70 \%, 80 \%, 90 \%$ and $100 \%(\mathrm{v} / \mathrm{v})$ ethanol solutions in water for $15 \mathrm{~min}$ each. Finally, the samples were air-dried, gold sputter-coated and imaged as described previously similarly to cell-free scaffold imaging.

Assessment of PEO/PCL/JFA scaffold swelling and degradation. Scaffold swelling was determined by placing pre-weighed scaffolds in $2 \mathrm{~mL}$ PBS in a shaking incubator at $37{ }^{\circ} \mathrm{C}, 5 \% \mathrm{CO}_{2}$ in air at 95\% relative humidity. At time intervals $(15,30,60,120$, 220 minutes, 10 days), scaffolds were removed from the PBS and excess liquid removed with tissue paper before weighing samples. The swelling ratio was calculated using the following formula:

$$
\text { Swelling ratio } \% Q=\left(W_{\mathrm{w}}-W_{\mathrm{d}}\right) / W_{\mathrm{d}} \times 100
$$

where dry weight is given as $W_{\mathrm{d}}$ and wet weight is given as $W_{\mathrm{w}}{ }^{25}$

Scaffold degradation in culture conditions was determined by placing pre-weighed scaffolds in $2 \mathrm{~mL}$ PBS in a shaking 
incubator at $37{ }^{\circ} \mathrm{C}, 5 \% \mathrm{CO}_{2}$ in air at $95 \%$ relative humidity. At different time intervals (5, 10 and 15 days) scaffolds were dried thoroughly and weighed again in order to determine weight loss. Weight loss was calculated using the following formula:

$$
\text { Weight loss \% }=\left(W_{\mathrm{o}}-W_{\mathrm{t}}\right) / W_{\mathrm{o}} \times 100
$$

where original weight is given as $W_{\mathrm{o}}$ and weight over time is given as $W_{\mathrm{t}}{ }^{25}$

\subsection{Statistical analysis}

Statistical analyses were performed using GraphPad Prism 7.03 software (San Diego, CA). For the physicochemical characterisation, groups were compared using an unpaired Student's $t$-test measured in triplicate. For cell experiments, triplicate technical replicates $(n=3)$ were carried out at $N=3$ independent experiments with ANOVA used for analysis. A value of $p \leq 0.05$ was considered significant, and graphs are reported as mean and standard deviation (SD).

\section{Results and discussion}

\subsection{Scaffold morphology}

PEO molecular weight affects PEO/PCL core/shell structure. PEO and PCL were selected to produce the electrospun fibres, as both are widely used in tissue engineering and for drug delivery applications. ${ }^{26}$ Moreover, their use to produce core/ shell electrospun fibres has been previously reported, ${ }^{27}$ due to their orthogonal solubility in non-miscible solvents and the favourable mechanical properties of PCL. At first, we examined the ability to electrospin PEO/PCL core/shell fibres by increasing PEO molecular weights from $200 \mathrm{kDa}$ to $400 \mathrm{kDa}$, and $900 \mathrm{kDa}$. The surface morphology and porosity of the resultant scaffolds were characterised by SEM and are shown in Fig. 1. The PEO/PCL (with PEO MW = $200 \mathrm{kDa}$ ) scaffold presented a regular surface and an average fibre diameter of $1.25 \mu \mathrm{m}$ (Fig. 1g). A higher average fibre diameter of $2 \mu \mathrm{m}$ was found when PEO $400 \mathrm{kDa}$ was used (Fig. S1b, ESI $\dagger$ ). This was as expected as it has been reported that for increased molecular weight, chain entanglement increases leading to a higher solution viscosity and consequently a higher fibre diameter. ${ }^{28}$

For both scaffolds fabricated with PEO $200 \mathrm{kDa}$ and $\mathrm{PEO}$ $400 \mathrm{kDa}$, the distinct core/shell structure of the fibres was confirmed by TEM (Fig. 1e and Fig. S1c, ESI $\dagger$ ). However, when PEO molecular weight was increased further to $900 \mathrm{kDa}$, no clear core/shell structure was observed under TEM, despite the presence of a stable jet during the electrospinning process (Fig. S1d, ESI $\dagger$ ). PEO $200 \mathrm{kDa}$ was chosen over PEO $400 \mathrm{kDa}$ for further development of the scaffold because the jet quality was found to be more stable for the PEO $200 \mathrm{kDa}$ during the electrospinning process.

JFA concentration affects PEO/PCL/JFA core/shell morphology. PCL scaffolds are generally considered to possess suitable mechanical properties and high solubility in organic solvents. However, PCL lacks suitable chemical groups for bioconjugation. $^{29,30}$ Therefore, PCL/JFA blends were used to provide suitable surface functionality for protein conjugation.

In Fig. 1, SEM images of PEO/PCL scaffolds display a limited internal pore structure whereas PEO/PCL/JFA scaffolds presented pores ranging from 1 to $16 \mu \mathrm{m}$, with an average pore size of $6 \mu \mathrm{m}$ (Fig. S2, ESI $\dagger$ ). This can be explained partially by the different electrospinning parameters used for both systems. A longer distance between the nozzle and collector was used for PEO/PCL, which resulted in a broader and less porous scaffold. The PEO/PCL/JFA jet was unstable with a longer distance and so this had to be reduced. Different JFA concentrations were tested during the optimisation process using similar electrospinning parameters to those used for PEO/PCL initially (with PEO $200 \mathrm{kDa}$ ). Changes were then made to these parameters until the most stable jet was obtained for all scaffolds with changing JFA content. It was found that the PEO/PCL/JFA scaffold morphology changed significantly depending on JFA concentration.

At $30 \%$ JFA, the scaffold presented smooth homogeneous fibres without defects (Fig. 1b) and a slightly higher average diameter of $1.4 \mu \mathrm{m}$ in comparison to PEO/PCL fibres $(1.25 \mu \mathrm{m})$ (Fig. $1 \mathrm{~g}$ and $\mathrm{h}$ ). Similarly to PEO/PCL scaffolds, distinct core/ shell structures were observed (Fig. 1f). During electrospinning, the Taylor cone (TC) was highly stable without interruption of the jet. When the JFA concentration was below or above $30 \%$, then the jet was unstable and the resulting scaffold was nonhomogeneous with variable fibre diameter and beading (Fig. 2). For example, in the cases of $5 \%, 6 \%$ and $7.5 \%$ JFA concentrations, the stability of the TC decreased and beads were formed (Fig. 2a-c). However, the jet became more stable and continuous when JFA concentrations increased. In fact, SEM images show a more homogeneous scaffold morphology for higher JFA concentrations with fewer beads observed. However, when the JFA concentration was above $30 \%$, the TC was disrupted by continuous fibre formation between the coaxial nozzle and the collector, resulting in the formation of a smaller scaffold with non-homogeneous fibres (Fig. 2e and f).

It was found that PCL/JFA solutions increased in conductivity with increasing JFA concentration levels. For the lowest concentrations $(5 \%, 6 \%, 7.5 \%)$, the conductivity was too low for electrospinning resulting in droplet formation. In contrast, the conductivity was high for the highest JFA concentrations (45\%, 60\%; $6.8 \mu \mathrm{S} \mathrm{cm} \mathrm{cm}^{-1}, 8.8 \mu \mathrm{S} \mathrm{cm} \mathrm{cm}^{-1}$ ) (Fig. $2 \mathrm{~g}$ ) with resulting continuous, irregular fibres. Among the concentrations investigated, it was thus identified that the optimal concentration level was 30\% JFA (Fig. 2d), and this was the formulation used for the rest of this study.

Aminolysis treatment time affects PEO/PCL fibre morphology. Aminolysis, i.e. reaction of multiple amine groups under strongly basic conditions at polyester residues, is widely used for the introduction of amino groups at polymer surfaces. ${ }^{31}$ Therefore, an alternative to the inclusion of JFA within the electrospun polymer blend was aminolysis of the PEO/PCL scaffold by exposure to 1,6-diaminohexane at $30 \mathrm{~min}$ intervals $(30 \mathrm{~min}, 1 \mathrm{~h}$

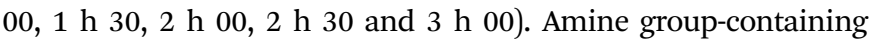
$\mathrm{PEO} / \mathrm{PCL}$ scaffolds are denoted as PEO/PCL-NH $\mathrm{N}_{2}$. The effect of aminolysis on PEO/PCL fibre morphology was observed by SEM 

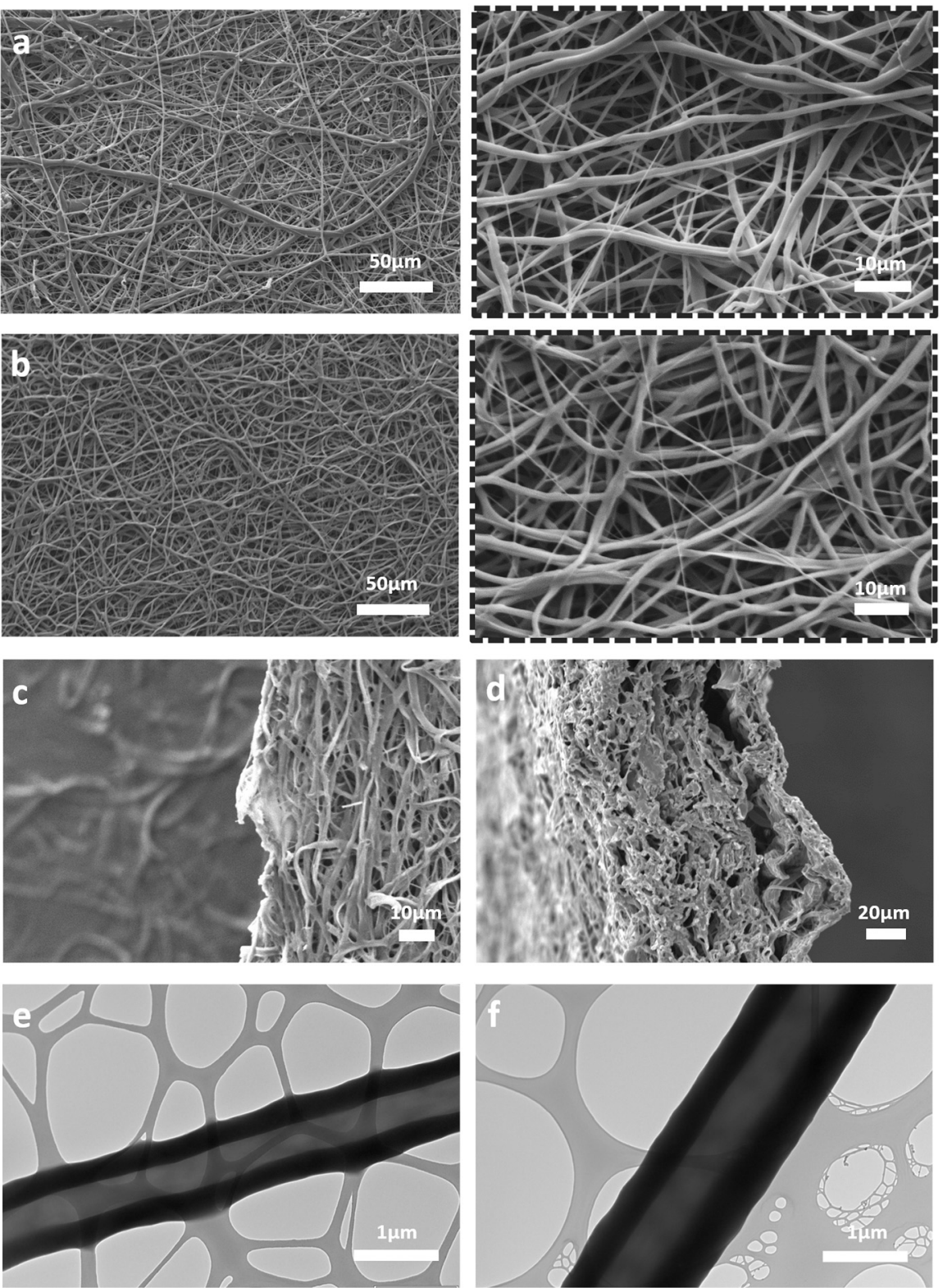

g

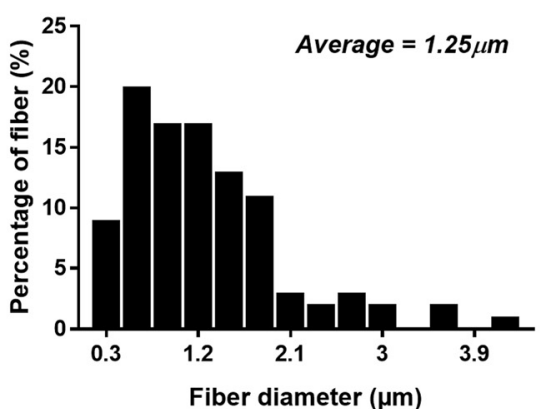

h

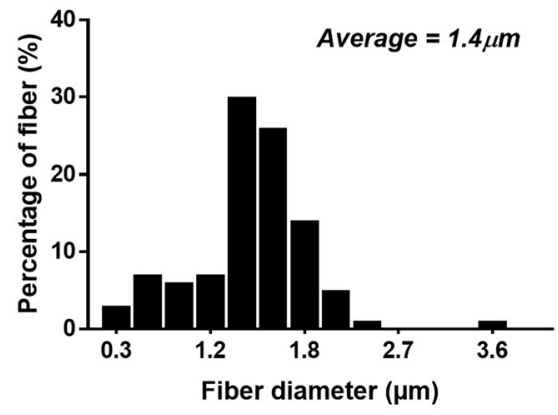

Fig. 1 Morphological characterisation (low and high magnification SEM images) of coaxial fibre morphology of (a) PEO/PCL and (b) PEO/PCL/JFA (JFA = 30\%). Cross-sectional SEM images via cryosectioning shows the difference in porous structure of the (c) PEO/PCL and (d) PEO/PCL/JFA scaffolds. TEM images showing the core-shell structure of individual fibres of (e) PEO/PCL and (f) PEO/PCL/JFA. Image quantification from SEM shows the histogram of the fibre diameter distribution of $(\mathrm{g}) \mathrm{PEO} / \mathrm{PCL}$ and (h) PEO/PCL/JFA. Data were generated from 100 measurements of fibre diameter using ImageJ software based on 25 measurements from five different SEM images. 

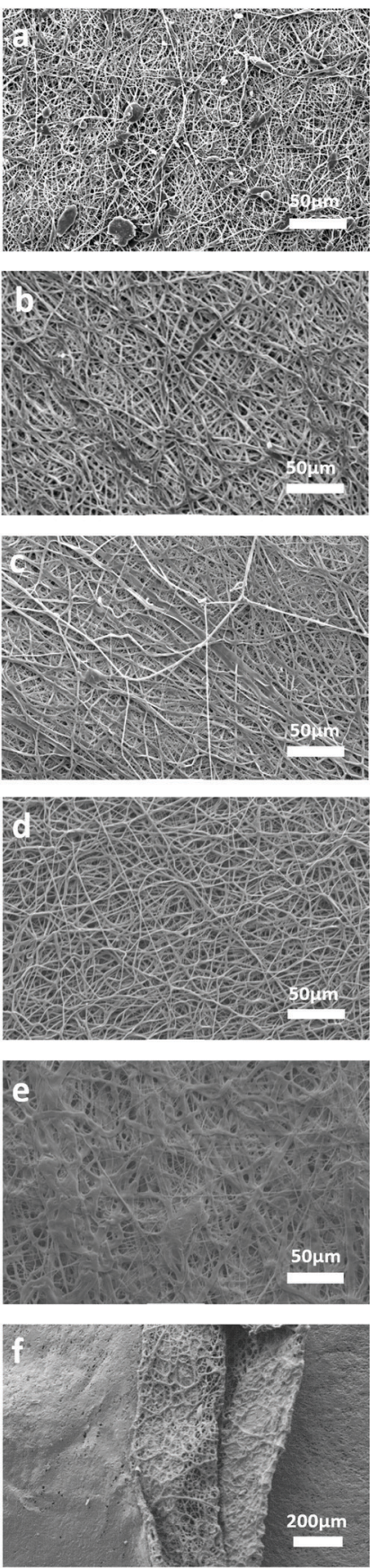
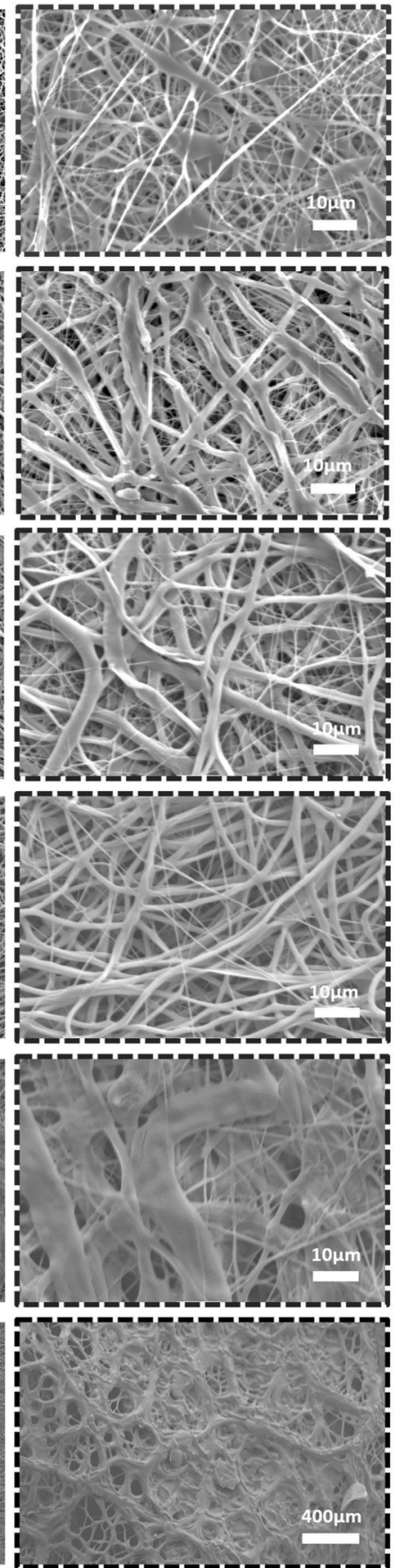

\section{g}

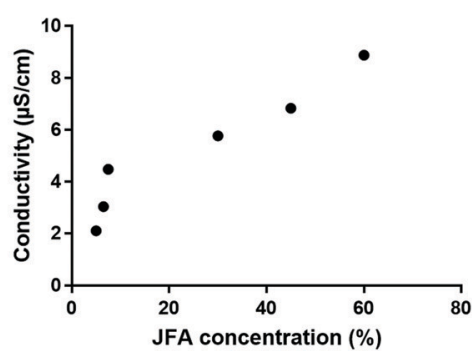

h

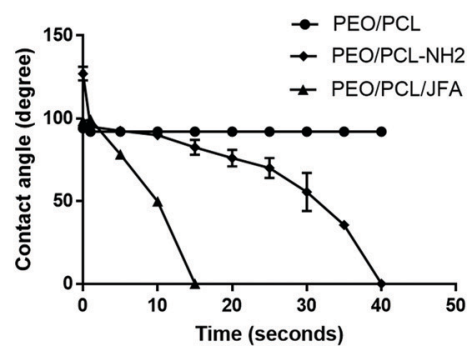

i

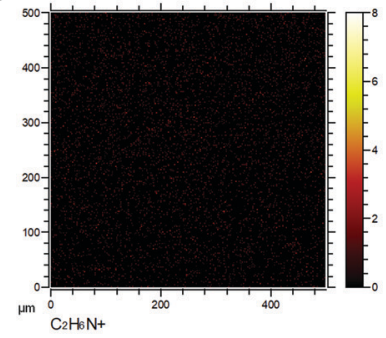

j

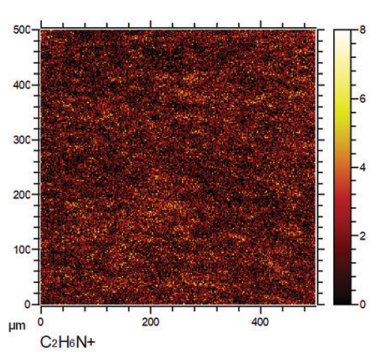

Fig. 2 Characterisation of PEO/PCL/JFA scaffolds: low and high magnification scanning electron microscopy (SEM) images of PEO/PCL/JFA showing fibre morphologies. Images were taken at different JFA concentrations, including (a) $5 \%$, (b) $6 \%$, (c) $7.5 \%$, (d) $30 \%$, (e) $45 \%$ and (f) $60 \%$. At $30 \%$ JFA, the scaffold presented smooth homogeneous fibres without defects. When the JFA concentration was below or above $30 \%$, the scaffold was nonhomogeneous. Graph (g) shows the conductivity of PCL/JFA solutions against JFA concentration, displaying an increase in conductivity with increasing JFA concentration (errors bars not visible due to very small standard deviations (h)). Hydrophilicity of the surface of the electrospun scaffolds was measured by a sessile drop technique, with deionised water and a CAM 200 sessile drop video capture apparatus. Graph shows the average WCA at every second after the water droplet came in contact with the sample for PEO/PCL, aminolyzed PEO/PCL, PEO/PCL/JFA. PEO/PCL, aminolyzed PEO/PCL, $\mathrm{PEO} / \mathrm{PCL} / \mathrm{JFA}$. PEO/PCL scaffolds exhibited a nominally hydrophobic surface with a stable WCA of $98^{\circ}$, whereas aminolyzed PEO/PCL and PEO/PCL/JFA scaffolds had dynamic WCAs starting respectively at $130^{\circ}$ and $98^{\circ}$. The measurements decreased progressively until the droplet was fully absorbed after 40 seconds and 20 seconds respectively for the aminolyzed PEO/PCL and PEO/PCL/JFA. Time-of-flight secondary ion mass spectrometry (TOF SIMS) analysis was performed to confirm the absence or presence of amino groups and characterise their distribution on the scaffold surface. Spectra were calibrated to $\mathrm{CH}, \mathrm{C}-2 \mathrm{H}, \mathrm{C}-3 \mathrm{H}, \mathrm{C}-4 \mathrm{H}$ and $\mathrm{C}-5 \mathrm{H}$ peaks. Ion maps for detection of $\mathrm{C}_{2} \mathrm{H}_{6} \mathrm{~N}^{+}$(used to detect JFA) for (i) PEO/PCL and (j) PEO/PCL/JFA, show that the $\mathrm{C}_{2} \mathrm{H}_{6} \mathrm{~N}^{+}$ion was present and distributed homogeneously across the surface of PEO/PCL/JFA scaffolds only. Values represented by mean values $\pm \mathrm{SD}(n=3)$, and images shown are representative of triplicate samples analysed. 
(Fig. S3, ESI $\dagger$ ). These images show no damage to the fibres between $30 \mathrm{~min}$ to $2 \mathrm{~h} 30$ of treatment. However, after 3 hours of exposure to 1,6-diaminohexane, several bead-like structures can be observed. XPS analysis showed an increased nitrogen peak for treated samples; however, the data showed that longer treatment times did not increase the detectable nitrogen content (Fig. S4, ESI $\dagger$ ). Therefore, it was decided to progress with an aminolysis treatment time of $30 \mathrm{~min}$ for protein conjugation.

\subsection{Scaffold surface analysis}

Water contact angle. Fig. $2 \mathrm{~h}$ and Fig. S5 (ESI $\dagger$ ) show water contact angles (WCA) of PEO/PCL, aminolyzed PEO/PCL-NH $\mathrm{N}_{2}$ and PEO/PCL/JFA scaffolds. PEO/PCL scaffolds exhibited a nominally hydrophobic surface with a stable WCA of $98^{\circ}$, whereas aminolyzed PEO/PCL- $\mathrm{NH}_{2}$ and PEO/PCL/JFA scaffolds had dynamic WCAs starting respectively at $130^{\circ}$ and $98^{\circ}$. The angles then decreased progressively until the droplet was fully absorbed after 40 seconds and 20 seconds respectively for the aminolyzed PEO/PCL-NH $\mathrm{N}_{2}$ and PEO/PCL/JFA scaffolds. These changes over time were likely due to the surfaces being rough but more wetted over a time period as the drops sank into the scaffold. Moreover, the lower WCA of aminolysed PEO/PCL-NH $\mathrm{N}_{2}$ and PEO/PCL/JFA scaffolds can be attributed to the presence of the amine group at the scaffold surface after aminolysis or integration of JFA with PCL, resulting in more hydrophilic surfaces. $^{18}$

Time-of-flight secondary ion mass spectrometry (TOF-SIMS). Further characterisation of the presence of amine groups at the surface of scaffolds prepared using JFA or aminolysis was carried out with TOF-SIMS. Results indicated that JFA was present homogeneously at the surface of the fibres, as indicated by $\mathrm{NH}_{4}{ }^{+}$(Fig. S6a, ESI $\dagger$ ) and $\mathrm{C}_{2} \mathrm{H}_{6} \mathrm{~N}^{+}$(Fig. S6b, ESI $\dagger$ ) peaks that were significantly higher than the PEO/PCL sample. Ion maps support this result and show homogeneous distribution of the $\mathrm{C}_{2} \mathrm{H}_{6} \mathrm{~N}^{+}$ion across the surface of the PEO/PCL/JFA scaffold. (Fig. $2 \mathrm{i}$ and $\mathrm{j}$ ). In contrast, the $\mathrm{NH}_{4}{ }^{+}$signal for PEO/PCL/JFA post-incubation in water at $37{ }^{\circ} \mathrm{C}$ for 7 days was lower than that observed beforehand and for the PEO/PCL scaffold (Fig. S6a, ESI $\dagger$ ). This could be attributed to the release of JFA into the water. TOF-SIMS also show a peak for $\mathrm{NH}_{4}{ }^{+}$for aminolyzed PEO/PCL (Fig. S6a, ESI $\dagger$ ). Additionally, $\mathrm{NH}_{4}{ }^{+}$peak areas are similar for $\mathrm{PEO} / \mathrm{PCL}-\mathrm{NH}_{2}\left(1.69 \times 10^{-3}\right)$ and PEO/PCL/JFA $\left(1.19 \times 10^{-3}\right)$, thus showing that the aminolysis treatment and JFA loading resulted in a similar amine group distribution across the surface of the scaffolds (Fig. S6a, ESI $\dagger$ ). In addition to XPS (Fig. $\mathrm{S} 4, \mathrm{ESI} \dagger)$, TOF-SIMS supports the hypothesis that amino groups were successfully introduced onto the scaffold surface using both methods (Fig. S6, ESI $\dagger$ ). Although XPS and TOF-SIMS were able to detect the presence of the nitrogen within the amine groups at the scaffold surface, neither method was able to determine the location on or within the fibres nor the distribution of amine groups over the length of the fibre.

\subsection{Mechanical properties of PEO/PCL and PEO/PCL/JFA scaffolds}

Tensile properties of PEO/PCL and PEO/PCL/JFA scaffolds were determined by stress-strain measurements (Fig. 3). These data show that the mechanical properties of the scaffolds changed when JFA was introduced into the blend. For example, the inclusion of JFA significantly reduced the modulus from 1.11 MPa to $0.73 \mathrm{MPa}$ (Fig. 3b), meaning that the elasticity of the modified scaffold was greater than for the PEO/PCL alone scaffold. It is likely that incorporation of JFA plasticised the PCL matrix and reduced polymer chain-chain interaction enthalpies. In contrast, the aminolysis procedure with 1,6-diaminohexane resulted in the reduction of the elasticity of the scaffold, compared with the untreated scaffold. This we attribute to crosslinking between adjacent polyester chains as the diamine reacted, leading to enhanced rigidity, as well as a reduction in PCL chain length as ester bonds were replaced with amides.

Assessment of PEO/PCL/JFA swelling and degradation in cell-culture condition. Swelling ratio performed on PEO/PCL/ JFA scaffold for up to $240 \mathrm{~min}$, showed that an equilibrium state is reached after $60 \mathrm{~min}$ at a swelling percentage of $350 \%$ (Fig. S8a, ESI $\dagger$ ).

Weight loss analysis was used to assess the degradation profile of the PEO/PCL/JFA scaffold for 15 days, which is the longest time we anticipate the use of the scaffold (Fig. S8b, ESI $\dagger$ ). The scaffold remained intact over this period of time, which was further confirmed by SEM images post cell culture (Fig. 6e).

\subsection{PEO/PCL-NH $\mathrm{N}_{2}$ scaffolds: conjugation of shell molecule HRP $_{\mathrm{SM}}$ and release of core molecule $\mathrm{HRP}_{\mathrm{CM}}$}

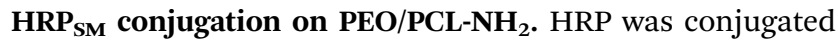
onto the scaffold surface by reacting the carboxyl groups of the protein with the amine groups introduced to the scaffold surface layers (by aminolysis or JFA). HRP was used as a model protein for surface conjugation and is denoted $\mathrm{HRP}_{\mathrm{SM}}$. The attachment of $\mathrm{HRP}_{\mathrm{SM}}$ to the PEO/PCL- $\mathrm{NH}_{2}$ scaffold was initially performed by simple adsorption of $\mathrm{HRP}_{\mathrm{SM}}$ at $37{ }^{\circ} \mathrm{C}$ to the surface of the scaffolds following the protocol described by Regis et al. ${ }^{23}$ Different adsorption times were used, including $15 \mathrm{~min}, 30 \mathrm{~min}, 45 \mathrm{~min}$ and $60 \mathrm{~min}$. $\mathrm{HRP}_{\mathrm{SM}}$ activity on the scaffold was then evaluated using the TMB assay. Protein activity increased with incubation time until $30 \mathrm{~min}$, then started to decrease with longer periods of incubation (Fig. S7, ESI $\dagger$ ) This suggested loss of the adsorbed protein, thus EDC-NHS coupling was performed after $30 \mathrm{~min}$ of $\mathrm{HRP}_{\mathrm{SM}}$ adsorption, covalently linking HRP to the surface of the scaffold. As apparent from Fig. 4a and b, activity of the conjugated HRP ${ }_{S M}$ was retained over two weeks, indicating successful covalent linking via the EDC-mediated procedure to anchor the protein to the fibre surface. In addition, protein conjugation to the scaffold surface, further supports the presence of amino groups at the fibre surface as determined using XPS and TOF-SIMS.

HRP $_{\text {CM }}$ release from PEO/PCL and PEO/PCL-NH N $_{2}$ scaffolds. HRP was loaded in the fibre core along with PEO and is denoted

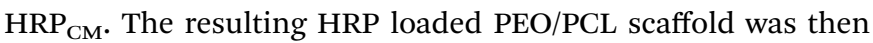
aminolysed. The resultant $\mathrm{HRP}_{\mathrm{CM}}$ release profiles from $\mathrm{PEO} /$ PCL and PEO/PCL-NH $\mathrm{N}_{2}$ scaffolds were compared in order to observe the effect of aminolysis on the protein release and its activity. Fig. $4 \mathrm{c}$ shows the release profile of $\mathrm{HRP}_{\mathrm{CM}}$ from the 
a

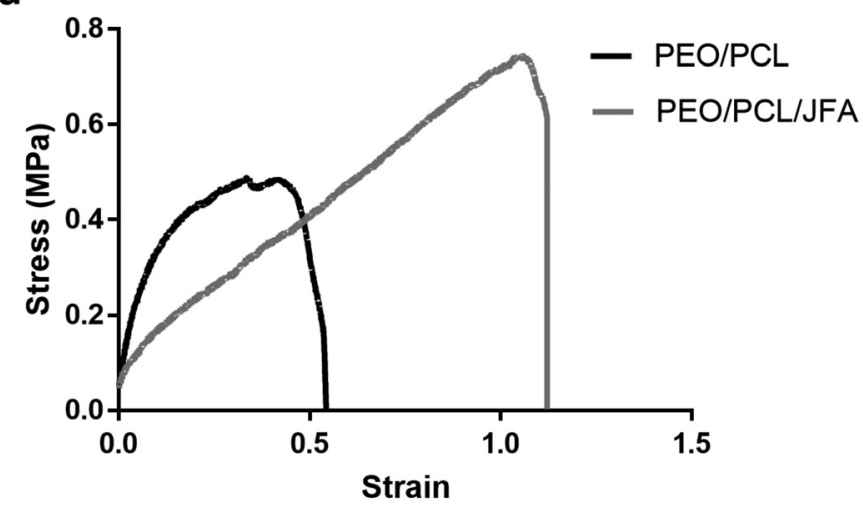

C

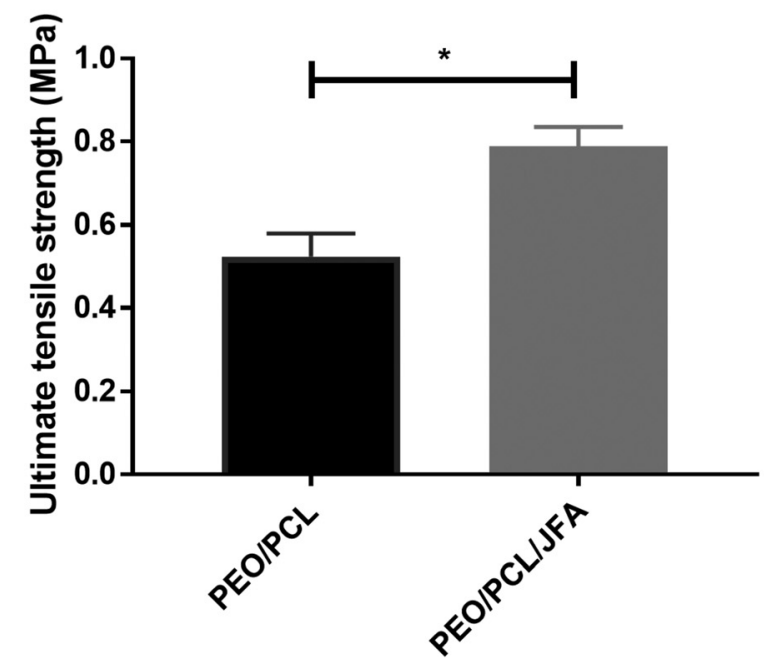

b

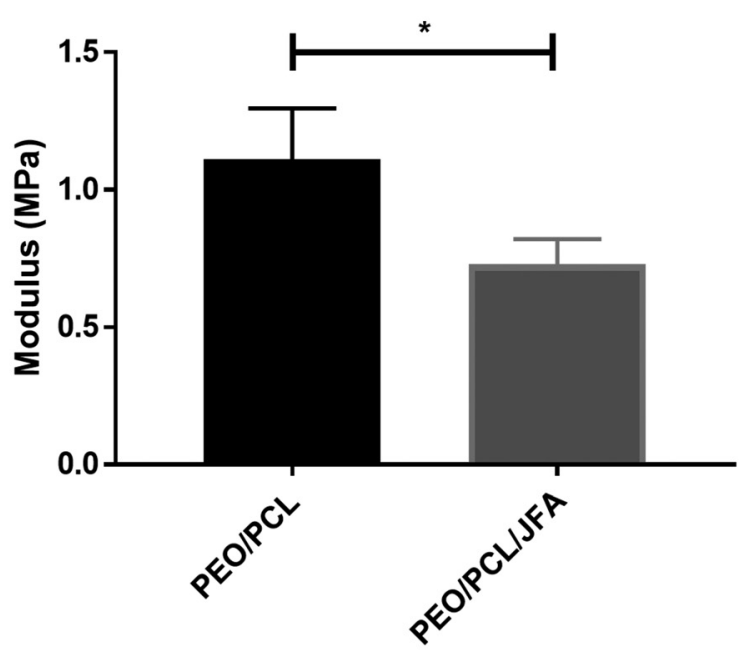

d

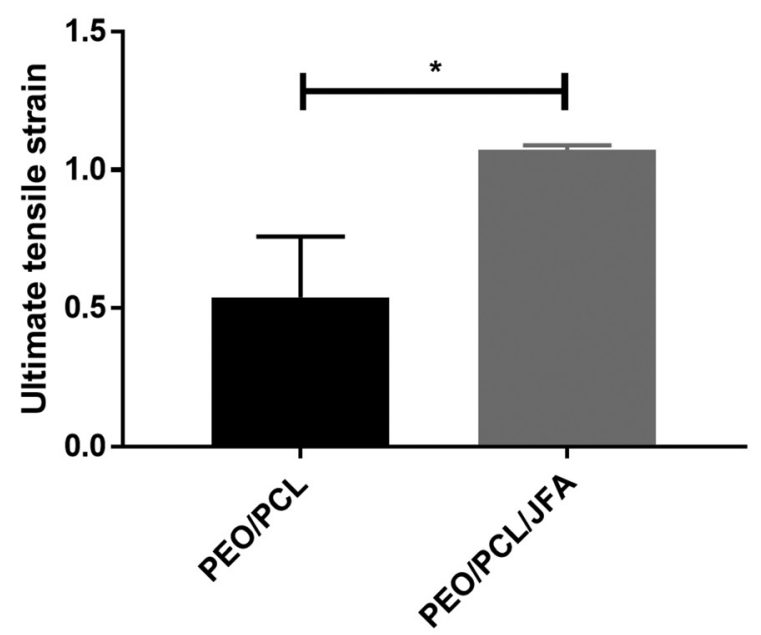

Fig. 3 Mechanical properties of PEO/PCL and PEO/PCL/JFA scaffolds. Tensile testing using a texture analyser was performed at room temperature, with a load cell capacity of $5 \mathrm{~N}$ and a cross-head speed of $10 \mathrm{~mm} \mathrm{~min}{ }^{-1}$. Representative stress-strain curves for PEO/PCL and PEO/PCL/JFA scaffolds are shown in (a). Young's modulus was calculated from the slopes of stress-strain curves and is shown in (b). Additionally, the ultimate tensile strength and the ultimate tensile strain were obtained from the stress-strain curves and are shown respectively in (c) and (d). Values represented by mean values \pm SD ( $n=3$; unpaired $t$-test; ${ }^{*} p \leq 0.05$ ).

PEO/PCL scaffold. During the first 8 hours, a burst release of $60 \%$ of the total protein was observed, followed by a sustained cumulative release of the remaining $30 \%$ over a period of up to 15 days. In total, $90 \%$ of HRP was released from PEO/PCL scaffold (Fig. 4c). ABTS results show that HRP was active in the media until the end of the release study (Fig. 4d). On the other hand, the PEO/PCL-NH $\mathrm{N}_{2}$ scaffold did not show any release of the $\mathrm{HRP}_{\mathrm{CM}}$ previously encapsulated in the core. The ABTS assay (Fig. 4d), showed protein activity only on the first day. This suggested that protein was lost during the aminolysis step conducted after electrospinning and therefore this approach was not optimal for introducing amine groups to the surface of the fibres already containing proteins encapsulated in the core. However, this method was suitable to functionalise fibres in the cases where payloads were subsequently immobilised or adsorbed to the surface (after aminolysis).

\subsection{PEO/PCL/JFA scaffolds: conjugation of shell molecule} HRP $_{S M}$ and release of core molecule $\mathrm{HRP}_{\mathrm{CM}}$

HRP $_{\text {SM }}$ conjugation on PEO/PCL-JFA scaffolds. The HRP $\mathrm{HM}_{\mathrm{SM}}$ was directly conjugated onto the amine-functional PEO/PCL/ JFA surface by first adsorbing the protein for $30 \mathrm{~min}$ and secondly treating the scaffold for an hour with EDC-NHS. The HRP $_{\text {SM }}$ activity was then evaluated using the TMB assay, with the data showing that the protein was still active $(6.23 \times$ $10^{-7} \mathrm{AU}$ ) after five days (Fig. 5a and b).

HRP $_{\mathbf{C M}}$ release from PEO/PCL/JFA scaffolds. HRP was loaded in the fibre core along $\mathrm{PEO}$ and is denoted $\mathrm{HRP}_{\mathrm{CM}}$. The release of $\mathrm{HRP}_{\mathrm{CM}}$ from $\mathrm{PEO} / \mathrm{PCL} / \mathrm{JFA}$ scaffolds was quantified by using a Micro-BCA assay.

Fig. $5 c$ shows a burst release of the loaded $\mathrm{HRP}_{\mathrm{CM}}$ of $60 \%$ within the first hour. Then $30 \%$ was released in the following three hours. The ABTS assay (Fig. 5d), showed that the released protein was active after $48 \mathrm{~h}$ of release. These experiments 
a

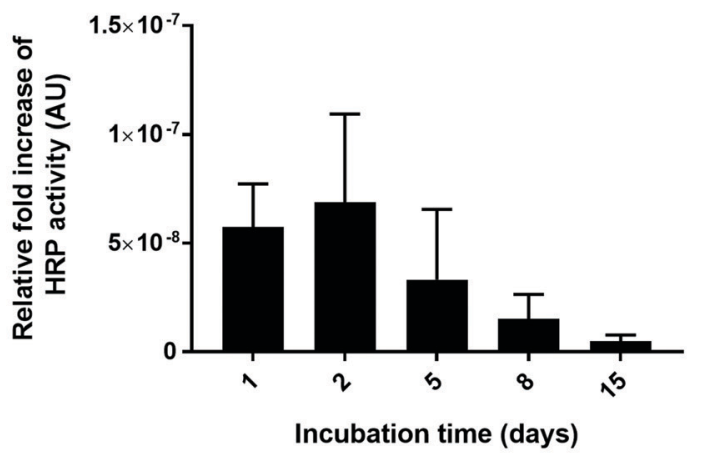

b

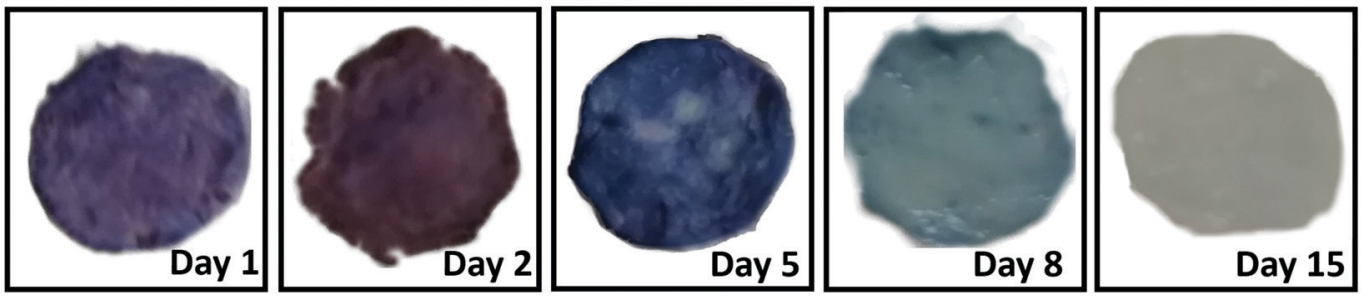

C

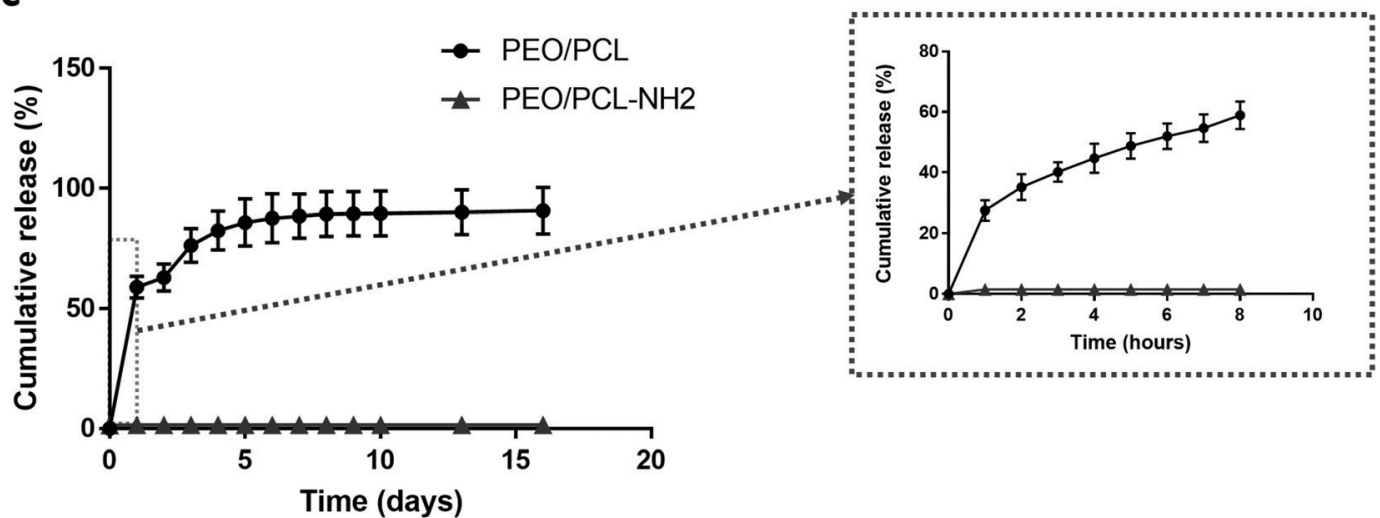

d

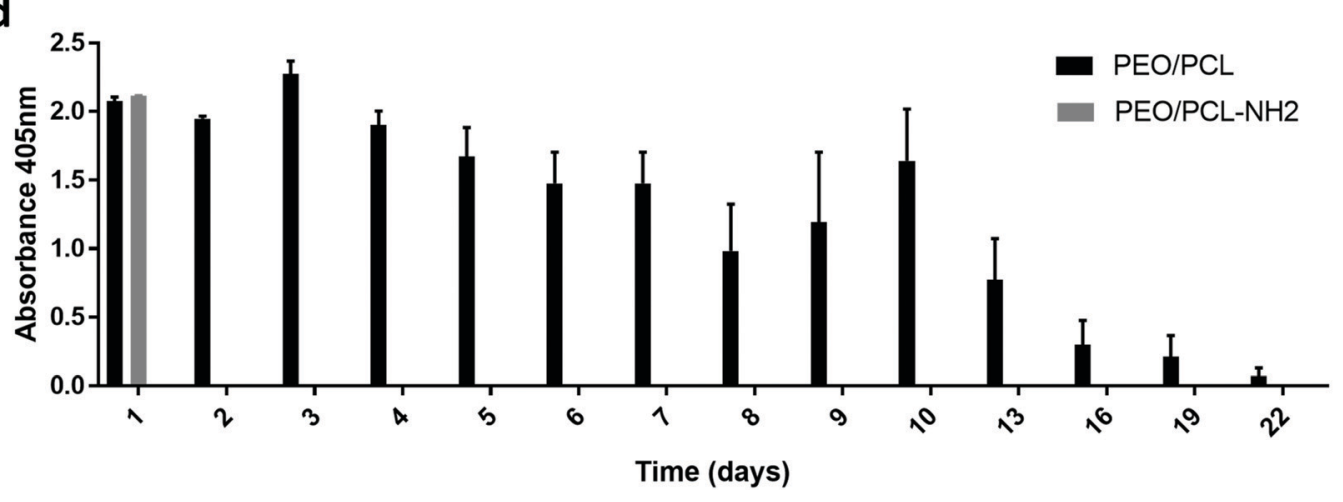

Fig. 4 Biphasic protein release from $\mathrm{PEO} / \mathrm{PCL}$ and $\mathrm{PEO} / \mathrm{PCL}-\mathrm{NH}_{2}$ scaffolds. HRP $\mathrm{SM}$ was conjugated onto the PEO/PCL-NH 2 Scaffold surface by first placing $10 \mathrm{~mm}$ diameter scaffolds in a HRP solution $\left(50 \mu \mathrm{g} \mathrm{mL}{ }^{-1}\right)$ for $30 \mathrm{~min}$ at $37^{\circ} \mathrm{C}$ in a shaking incubator. The scaffolds were then treated with EDC-NHS chemistry for an hour at room temperature. Finally, the scaffolds were placed in PBS in a shaking incubator at $37^{\circ} \mathrm{C}$, for a period of 15 days. $\mathrm{HRP}_{S M}$ activity was assessed after 1, 2, 5, 8 and 15 days of incubation by placing the scaffold in 3,3',5,5' -tetramethylbenzidine substrate solution (TMB) for $15 \mathrm{~min}$ and reading the absorbance of the supernatant at $405 \mathrm{~nm}$. (a) Graph showing the TMB colour intensity on the scaffold surface quantified by ImageJ. All samples were normalised to the control PEO/PCL/JFA blank scaffold. Values represented by mean values $\pm \mathrm{SD}(n=3)$. (b) Pictures of the scaffolds with background correction after the TMB assay. $\mathrm{HRP}_{\mathrm{CM}}$ release profiles from pre-weighed loaded PEO/PCL and PEO/PCL-NH 2 fibres were carried out in a shaking incubator at $37^{\circ} \mathrm{C}$ for 22 days in PBS. At predefined time intervals, $1 \mathrm{~mL}$ of the supernatant was withdrawn and replaced with an equal volume of fresh PBS each time. (c) Graph showing the protein concentration measured post-release in the media by MicroBCA assay. Values represented by mean values $\pm \mathrm{SD}(n=3)$. (d) Graph showing the protein activity measured post-release in PBS using the 2,2'-azino-bis(3ethylbenzothiazoline-6-sulfonic acid) diammonium salt (ABTS) assay. Values represented by mean values $\pm \operatorname{SD}(n=3)$. 
a

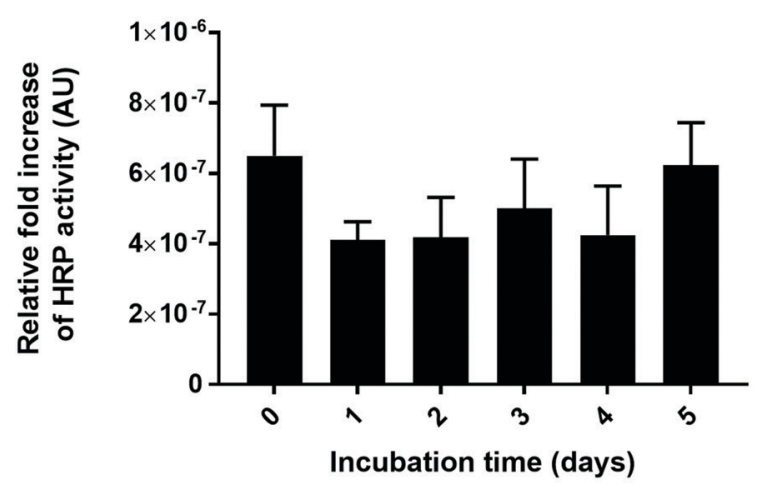

b

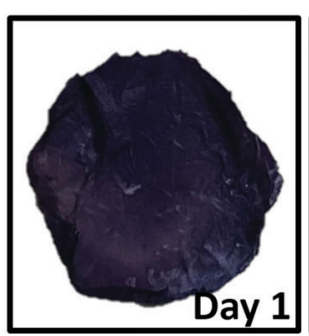

C

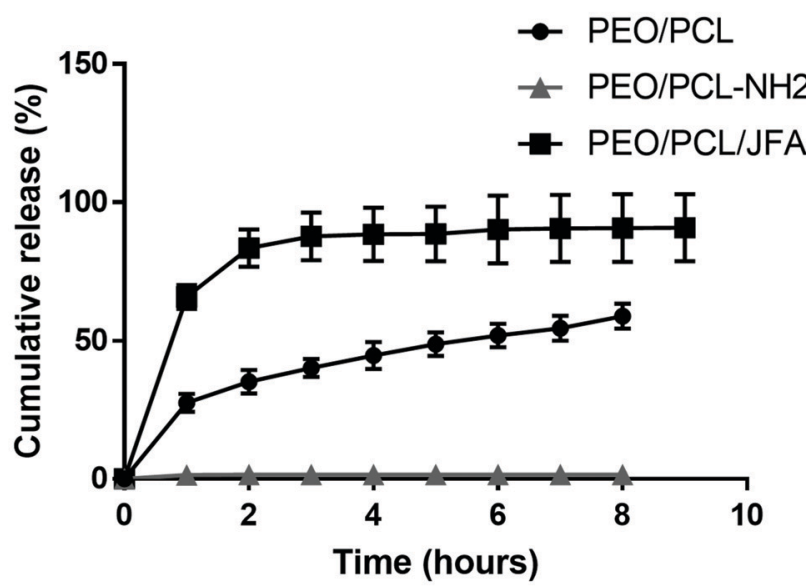

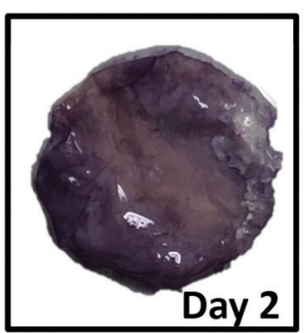
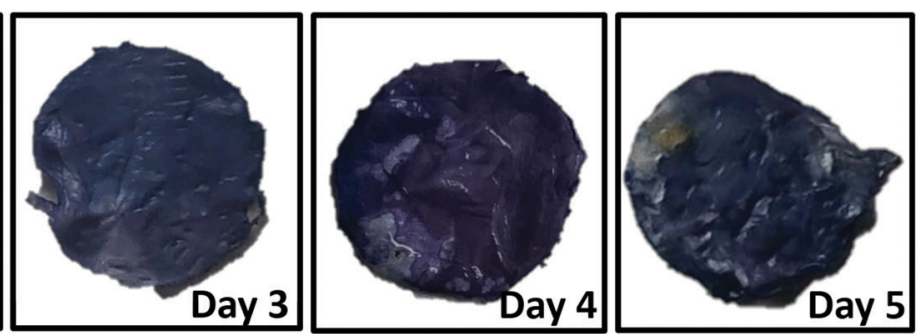

d

Fig. 5 Biphasic protein release from PEO/PCL and PEO/PCL/JFA scaffolds. HRP SM activity was assessed after 1 hour, 1, 2, 3, 4, and 5 days of incubation by placing the scaffold in 3,3',5,5'-tetramethylbenzidine substrate solution (TMB) for $15 \mathrm{~min}$. (a) Graph showing the TMB colour intensity on the scaffold surface quantified by ImageJ. All samples were normalised to the control PEO/PCL/JFA blank scaffold. Values represented by mean values \pm SD $(n=3)$. (b) Pictures of the scaffolds with background correction after the TMB assay. $\mathrm{HRP}_{\mathrm{CM}}$ release profiles from pre-weighed loaded $\mathrm{PEO} / \mathrm{PCL}, \mathrm{PEO} / \mathrm{PCL}-\mathrm{NH} \mathrm{H}_{2}$ and PEO/PCL/JFA fibres were carried out in a shaking incubator at $37{ }^{\circ} \mathrm{C}$ for 96 hours in PBS. At predefined time intervals, $1 \mathrm{~mL}$ of the medium was withdrawn and replaced with an equal volume of fresh medium each time. (c) Graph showing the protein concentration measured post-release in the media by MicroBCA assay. Values represented by mean values \pm SD $(n=3)$. (d) Graph showing the protein activity measured post-release in the media using the 2,2' -azino-bis(3-ethylbenzothiazoline-6-sulfonic acid) diammonium salt (ABTS) assay. Values represented by mean values \pm SD $(n=3)$.

indicated that the mixed functional fibre system coaxial electrospun PEO/PCL/JFA fibres allowed the simultaneous release of protein from the core of the fibres and the immobilisation of another protein, with retention of activity, on the same scaffold.

\subsection{Scaffold cytocompatibility and biological response}

The cellular responses to PEO/PCL/JFA scaffolds with biological molecules incorporated were evaluated with respect to cell attachment and albumin secretion by HepG2 cells.
Cell attachment on a BSA-conjugated scaffold. Koblinski et al. have demonstrated the ability of BSA to trigger cell attachment on surfaces that originally presented a low level of adhesion proteins to cells in vitro. These proteins, which can originate from the ECM or serum, are usually necessary to help cells adhere to their surroundings. ${ }^{32}$ HepG2 cells were cultured on blank (PEO/PCL/JFA scaffolds) and BSA-conjugated scaffolds (PEO/PCL/JFA-BSA scaffolds) for 3 hours. Cell viability was evaluated with a Live/Dead ${ }^{\mathrm{TM}}$ stain and their metabolic activity was assessed using PrestoBlue ${ }^{\mathrm{TM}}$. HepG2 cells attached to both 
a

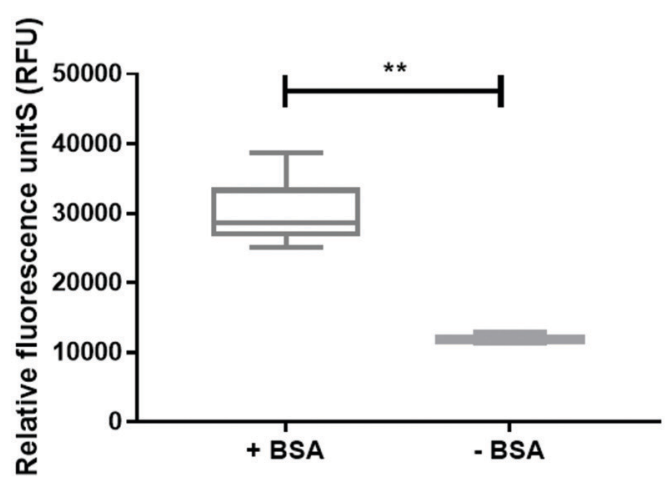

C
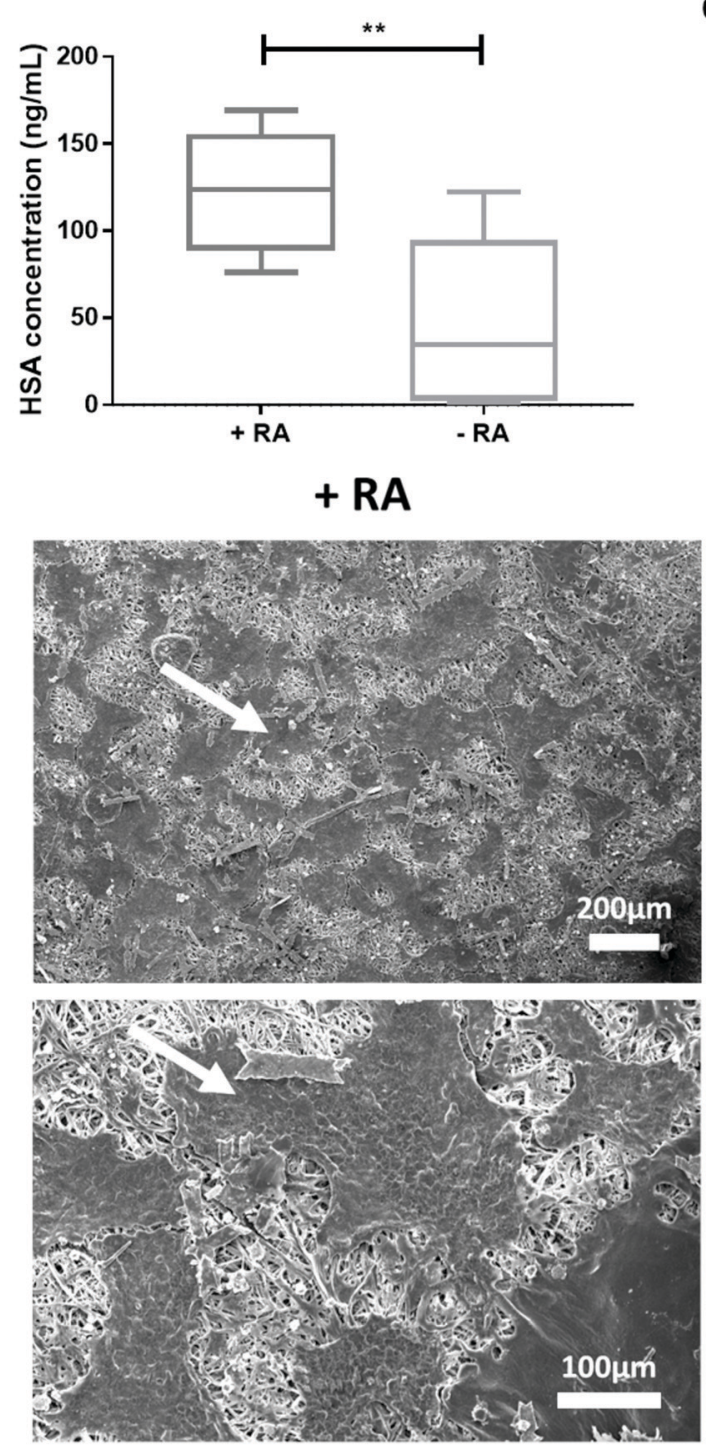

b

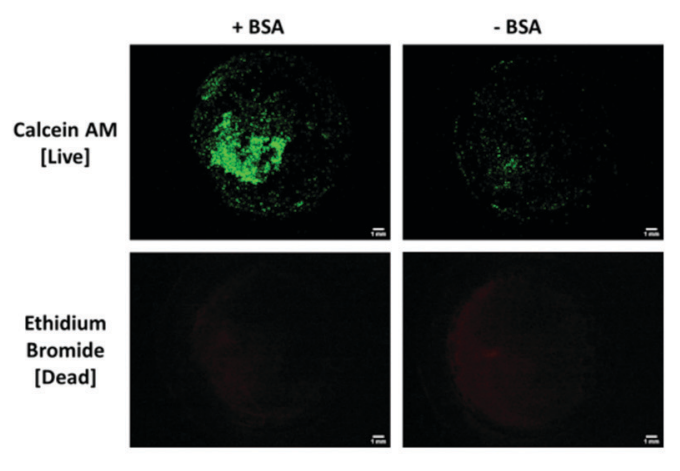

d
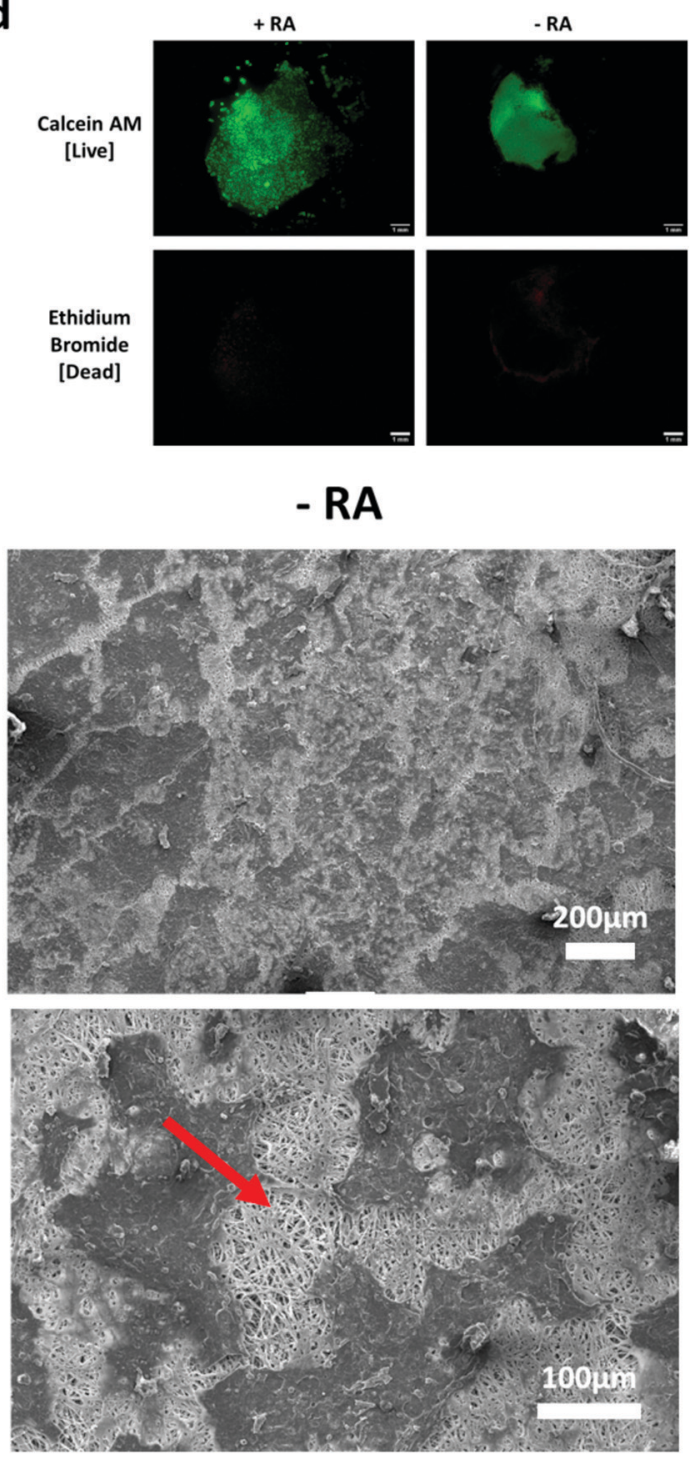

Fig. 6 (a) HepG2 adhesion to BSA-functionalised PEO/PCL/JFA scaffolds $3 \mathrm{~h}$ post-seeding as measured by the PrestoBlue assay. Values represented by mean values $\pm \mathrm{SD}\left(n \geq 3,{ }^{* *} p<0.01 ; 2\right.$ independent experiments); (b) live-dead (Calcein AM and ethidium bromide) staining of HepG2 cells $3 \mathrm{~h}$ postseeding on BSA functionalised and blank PEO/PCL/JFA scaffolds. (c) Human serum albumin quantification of culture media using ELISA with retinoic acid-containing (RA) and blank electrospun PEO/PCL/JFA scaffolds. Values represented by mean values \pm SD $(n \geq 7 ; 3$ independent experiments $N=3$; unpaired $t$-test; ${ }^{* \star} p<0.01$ ), (d) live-dead (Calcein AM and ethidium bromide) staining of HepG2 cells 6 d post-seeding on RA-loaded and blank PEO/ PCL/JFA scaffolds and (e) SEM images after 6 days of HepG2 culture on RA loaded and blank PEO/PCL/JFA scaffolds. Cells are indicated by a white arrow. Intact fibres are shown with a red arrow. 
scaffolds (Fig. 6a and b), however BSA-conjugated scaffolds showed significantly higher cell attachment relative to the control scaffolds (no BSA conjugation; 2.5 fold increase). In addition, the metabolic activity was significantly higher when cells were cultured on BSA-conjugated scaffolds than compared to non BSA-conjugated materials (Fig. 6a). Live/ Dead $^{\mathrm{TM}}$ staining confirmed this further, with a significantly higher viability for cells cultured on BSA-conjugated scaffolds (as determined from image analysis).

Assessment of albumin secretion using RA-loaded PEO/PCL/ JFA scaffolds. Burley et al. demonstrated the potential of RA to increase of the levels of albumin and urea secretion from HepG2 cells. $^{33}$ We therefore chose to use RA as a model cell-modifier to assess cellular response, as its effect on HepG2 cells could be quantified by measuring albumin secretion. RA-loaded PEO/PCL/JFA scaffolds were prepared as described above by loading RA into the core. To observe the effect of RA-loaded PEO/PCL/JFA scaffolds on HepG2 albumin secretion, we seeded cells on blank and RA-loaded scaffolds. Human serum albumin (HSA) was quantified in the supernatant after six days of culture using ELISA (Fig. 6c). Cell viability was also evaluated with a Live/Dead ${ }^{\mathrm{TM}}$ stain (Fig. 6d) and SEM imaging (Fig. 6e). Live/Dead ${ }^{\mathrm{TM}}$ staining showed a high viability on both RA and non-RA loaded scaffolds. Additionally, SEM images showed that cells adopted a spread morphology across the surface. We observed that HepG2 cells cultured on RA-loaded PEO/PCL/JFA scaffolds secreted significantly higher levels of HSA ( $\sim 2.7$ fold increase) relative to cells cultured on the control blank PEO/PCL/JFA scaffolds. Fig. 6 shows that the cells were viable on the control (PEO/PCL/JFA), RA-loaded and BSA-conjugated PEO/PCL/JFA scaffolds. This demonstrated the biocompatibility of the different scaffolds with HepG2 cells at the different stages of scaffold fabrication, including postelectrospinning and post-surface conjugation.

\section{Conclusion}

In conclusion, aminolyzed PEO/PCL and PEO/PCL/JFA electrospun scaffolds were successfully fabricated and characterised. We showed that the use of JFA in a coaxial electrospun scaffold, facilitates the production of a multiple protein delivery fibrous system. In contrast, aminolysis treatment, which is considered as the gold standard for surface functionalisation, was suitable for the surface functionalisation of the scaffolds but was not suitable when a bioactive was loaded in the core due to loss of the bioactivity during aminolysis. We conclude here therefore that the use of JFA does not affect the stability of a pre-loaded protein in the core enabling the simultaneous incorporation of multiple proteins in the same scaffold without affecting their activity. Additionally, surface analysis and mechanical characterisation showed that JFA rendered the scaffold more elastic than PEO/ PCL fibres alone. Finally, the biocompatibility of surface functionalisation of the PEO/PCL/JFA fibre scaffolds was confirmed, and modulation of cellular responses to the incorporated bioactive molecules were successfully demonstrated. ${ }^{34,35}$

\section{Conflicts of interest}

There are no conflicts to declare.

\section{Acknowledgements}

This work was supported by the Engineering and Physical Sciences Research Council (EPSRC) and Medical Research Council (MRC) Centre for Doctoral Training in Regenerative Medicine (EP/L015072/1) doctoral training grant awarded to IA. We would like to thank Ms Denise McLean and Ms Emily Smith from the University of Nottingham Nanoscale and Microscale Research Centre (nmRC) for their help with TEM and XPS respectively.

\section{References}

1 R. Censi, P. Di Martino, T. Vermonden and W. E. Hennink, Hydrogels for Protein Delivery in Tissue Engineering, J. Controlled Release, 2012, 161, 680-692.

2 M. Okamoto, Handbook of Tissue Engineering Scaffolds, 2019, vol. 1.

3 B. P. Chan and K. W. Leong, Scaffolding in Tissue Engineering: General Approaches and Tissue-Specific Considerations, Eur. Spine J., 2008, 17(suppl 4), 467-479.

4 X. Gao, S. Han, R. Zhang, G. Liu and J. Wu, Progress in Electrospun Composite Nanofibers: Composition, Performance and Applications for Tissue Engineering, J. Mater. Chem. B, 2019, 7, 7075-7089.

5 P. Rebulla and L. Lecchi, Towards Responsible Cord Blood Banking Models, Cell Proliferation, 2011, 44(suppl 1), 30-34.

6 M. R. Battig, B. Soontornworajit and Y. Wang, Programmable Release of Multiple Protein Drugs from AptamerFunctionalized Hydrogels Via Nucleic Acid Hybridization, J. Am. Chem. Soc., 2012, 134, 12410-12413.

7 S. Kobsa and W. M. Saltzman, Bioengineering Approaches to Controlled Protein Delivery, Pediatr. Res., 2008, 63(5), 513-519.

8 N. Bhardwaj and S. C. Kundu, Electrospinning: A Fascinating Fiber Fabrication Technique, Biotechnol. Adv., 2010, 28, 325-347.

9 Y. Li, F. Chen, J. Nie and D. Yang, Electrospun Poly(Lactic Acid)/Chitosan Core-Shell Structure Nanofibers from Homogeneous Solution, Carbohydr. Polym., 2012, 90, 1445-1451.

10 S. Agarwal, J. H. Wendorff and A. Greiner, Use of Electrospinning Technique for Biomedical Applications, Polymer, 2008, 49, 5603-5621.

11 T. T. T. Nguyen, O. H. Chung and J. S. Park, Coaxial Electrospun Poly(Lactic Acid)/Chitosan (Core/Shell) Composite Nanofibers and Their Antibacterial Activity, Carbohydr. Polym., 2011, 86, 1799-1806.

12 R. A. Perez and H. W. Kim, Core-Shell Designed Scaffolds for Drug Delivery and Tissue Engineering, Acta Biomater., 2015, 21, 2-19.

13 D. Han and A. J. Steckl, Coaxial Electrospinning Formation of Complex Polymer Fibers and Their Applications, ChemPlusChem, 2019, 84, 1453-1497. 
14 H. Jiang, L. Wang and K. Zhu, Coaxial Electrospinning for Encapsulation and Controlled Release of Fragile WaterSoluble Bioactive Agents, J. Controlled Release, 2014, 193, 296-303.

15 G. S. Schultz and A. Wysocki, Interactions between Extracellular Matrix and Growth Factors in Wound Healing, Wound Repair Regen., 2009, 17, 153-162.

16 A. C. B. Allen, E. Barone, C. O. K. Crosby, L. J. Suggs and J. Zoldan, Electrospun Poly(N-Isopropyl Acrylamide)/ Poly(Caprolactone) Fibers for the Generation of Anisotropic Cell Sheets, Biomater. Sci., 2017, 5, 1661-1669.

17 M. Cobos, J. R. Ramos, D. J. Guzman, M. D. Fernandez and M. J. Fernandez, Pcl/Poss Nanocomposites: Effect of Poss Derivative and Preparation Method on Morphology and Properties, Polymers, 2018, 11.

18 I. Aldalur, H. Zhang, M. Piszcz, U. Oteo, L. M. RodriguezMartinez, D. Shanmukaraj, T. Rojo and M. Armand, Jeffamine ${ }^{\circledR}$ Based Polymers as Highly Conductive Polymer Electrolytes and Cathode Binder Materials for Battery Application, J. Power Sources, 2017, 347, 37-46.

19 L. Mascia, R. Su, J. Clarke, Y. Lou and E. Mele, Fibres from Blends of Epoxidized Natural Rubber and Polylactic Acid by the Electrospinning Process: Compatibilization and Surface Texture, Eur. Polym. J., 2017, 87, 241-254.

20 M. Ignatova, N. Stoyanova, N. Manolova, I. Rashkov, R. Kukeva, R. Stoyanova, R. Toshkova and A. Georgieva, Electrospun Materials from Polylactide and Schiff Base Derivative of Jeffamine $\operatorname{Ed}(\mathrm{R})$ and 8-Hydroxyquinoline-2Carboxaldehyde and Its Complex with $\mathrm{Cu}(2+)$ : Preparation, Antioxidant and Antitumor Activities, Mater. Sci. Eng., C, 2020, 116, 111185.

21 U. Stachewicz, C. A. Stone, C. R. Willis and A. H. Barber, Charge Assisted Tailoring of Chemical Functionality at Electrospun Nanofiber Surfaces, J. Mater. Chem., 2012, 22, 22935.

22 F. Causa, E. Battista, R. Della Moglie, D. Guarnieri, M. Iannone and P. A. Netti, Surface Investigation on Biomimetic Materials to Control Cell Adhesion: The Case of Rgd Conjugation on Pcl, Langmuir, 2010, 26, 9875-9884.

23 S. Regis, S. Youssefian, M. Jassal, M. D. Phaneuf, N. Rahbar and S. Bhowmick, Fibronectin Adsorption on Functionalized Electrospun Polycaprolactone Scaffolds: Experimental and Molecular Dynamics Studies, J. Biomed. Mater. Res., Part A, 2014, 102, 1697-1706.

24 J. Schindelin, et al., Fiji: An Open-Source Platform for Biological-Image Analysis, Nat. Methods, 2012, 9, 676-682.
25 S. B. Qasim, S. Najeeb, R. M. Delaine-Smith, A. Rawlinson and I. Ur Rehman, Potential of Electrospun Chitosan Fibers as a Surface Layer in Functionally Graded Gtr Membrane for Periodontal Regeneration, Dent. Mater., 2017, 33, 71-83.

26 D. Fernandez, M. Guerra, J. G. Lisoni, T. Hoffmann, R. Araya-Hermosilla, T. Shibue, H. Nishide, I. MorenoVilloslada and M. E. Flores, Fibrous Materials Made of Poly(Epsilon-Caprolactone)/Poly(Ethylene Oxide)-BPoly(Epsilon-Caprolactone) Blends Support Neural Stem Cells Differentiation, Polymers, 2019, 11, 1621, DOI: 10.3390/polym11101621.

27 M. Rubert, J. Dehli, Y.-F. Li, M. B. Taskin, R. Xu, F. Besenbacher and M. Chen, Electrospun Pcl/Peo Coaxial Fibers for Basic Fibroblast Growth Factor Delivery, J. Mater. Chem. B, 2014, 2, 8538-8546.

28 R. Nayak, R. Padhye, I. L. Kyratzis, Y. B. Truong and L. Arnold, Effect of Viscosity and Electrical Conductivity on the Morphology and Fiber Diameter in Melt Electrospinning of Polypropylene, Text. Res. J., 2012, 83, 606-617.

29 R. Dwivedi, S. Kumar, R. Pandey, A. Mahajan, D. Nandana, D. S. Katti and D. Mehrotra, Polycaprolactone as Biomaterial for Bone Scaffolds: Review of Literature, J. Oral Biol. Craniofac. Res., 2020, 10, 381-388.

30 Y. He, R. D. Wildman, C. J. Tuck, S. D. Christie and S. Edmondson, An Investigation of the Behavior of Solvent Based Polycaprolactone Ink for Material Jetting, Sci. Rep., 2016, 6, 20852.

31 T. Haddad, S. Noel, B. Liberelle, R. El Ayoubi, A. Ajji and G. De Crescenzo, Fabrication and Surface Modification of Poly Lactic Acid (Pla) Scaffolds with Epidermal Growth Factor for Neural Tissue Engineering, Biomatter, 2016, 6, e1231276.

32 J. E. Koblinski, M. Wu, B. Demeler, K. Jacob and H. K. Kleinman, Matrix Cell Adhesion Activation by NonAdhesion Proteins, J. Cell Sci., 2005, 118, 2965-2974.

33 R. Michelle and C. M. R. Burley, Effects of Retinoic Acid on Proliferation and Differentiation of Hepg2, Open Biotechnol. J., 2007, 1, 47-51.

34 S. Chen, J. V. John, A. McCarthy and J. Xie, New Forms of Electrospun Nanofiber Materials for Biomedical Applications, J. Mater. Chem. B, 2020, 8, 3733-3746.

35 F. F. R. Damanik, G. Spadolini, J. Rotmans, S. Fare and L. Moroni, Biological Activity of Human Mesenchymal Stromal Cells on Polymeric Electrospun Scaffolds, Biomater. Sci., 2019, 7, 1088-1100. 